\title{
Treprostinil for pulmonary hypertension
}

\author{
Nika Skoro-Sajer' \\ Irene Lang' \\ Robert Naeije ${ }^{2}$ \\ 'Division of Cardiology, Department \\ of Internal Medicione II, Vienna \\ General Hospital, Medical University \\ of Vienna, Austria; ${ }^{2}$ Department \\ of Cardiology, Erasme University \\ Hospital, Brussels, Belgium
}

\begin{abstract}
Treprostinil is a stable, long-acting prostacyclin analogue which can be administered as a continuous subcutaneous infusion using a portable miniature delivery system. Subcutaneous treprostinil has been shown in a large multicenter randomized controlled trial to improve exercise capacity, clinical state, functional class, pulmonary hemodynamics, and quality of life in patients with pulmonary arterial hypertension, an uncommon disease of poor prognosis. Side effects include facial flush, headache, jaw pain, abdominal cramping, and diarrhea, all typical of prostacyclin, and manageable by symptom-directed dose adjustments, and infusion site pain which may make further treatment impossible in $7 \%-10 \%$ of the patients. Long-term survival in pulmonary arterial hypertension patients treated with subcutaneous treprostinil is similar to that reported with intravenous epoprostenol. There are uncontrolled data suggesting efficacy of subcutaneous treprostinil in chronic thromboembolic pulmonary hypertension. Treprostinil can also be administered intravenously, although increased doses, up to 2-3 times those given subcutaneously, appear to be needed to obtain the same efficacy. Preliminary results of a randomized controlled trial of inhaled treprostinil on top of bosentan and sildenafil therapies have shown significance on the primary endpoint, which was exercise capacity as assessed by the distance walked in 6 minutes. Trials of oral formulations of treprostinil have been initiated.
\end{abstract}

Keywords: pulmonary hypertension, prostacyclin, epoprostenol, treprostinil, congenital heart disease, connective tissue disease, portal hypertension, HIV infection, anorexigens

\section{Introduction}

Treprostinil is used to treat pulmonary arterial hypertension (PAH), which is a dyspnea-fatigue syndrome defined by an isolated increase in pulmonary vascular resistance (PVR) leading to progressive right heart failure (Farber and Loscalzo 2004). In spite of remarkable advances achieved with the introduction of prostacyclins, endothelin receptor antagonists (ERA), and phosphodiesterase-5 (PDE-5) inhibitors (Humbert et al 2004), the prognosis of PAH remains unfavorable, with estimated medial life expectancies of 5-6 years, and insufficient clinical improvement in about half of the survivors after 1-2 years (McLaughlin et al 2004; Provencher et al 2006).

PAH occurs in association with a variety of conditions, which include connective tissue diseases (CTD), congenital heart diseases (CHD), portal hypertension, human immunodeficiency virus (HIV) infection, and intake of appetite-suppressant drugs, mainly fenfluramines (Simmoneau et al 2004). Recently reported incidences and prevalences of PAH range from 2.4 to 7.6 cases per million/year and 15 to 52 per million respectively (Humbert et al 2006; Peacock et al 2007).

The diagnosis of PAH is based on a right heart catheterization to demonstrate a mean pulmonary artery pressure (Ppa) higher than $25 \mathrm{mmHg}$ at rest and $30 \mathrm{mmHg}$ at exercise, a normal left atrial pressure, estimated by a pulmonary artery wedge pressure (Ppw) of less than $15 \mathrm{mmHg}$, a PVR of more than 240 dyne. $\mathrm{s} . \mathrm{cm}^{-5}$, and a systematic work-up to exclude left heart failure with increased pulmonary venous pressure, respiratory diseases and/or hypoxemia, and chronic thromboembolic pulmonary hypertension (CTEPH) (Galie et al 2004; Badesch et al 2007). 
Until in the early 1990s, PAH was a uniformly fatal disease, with a median life expectancy of about 2.5 years. Uncontrolled studies showed that a small proportion of patients responded to high-dose calcium channel blockers, retrospective studies supported the use of anticoagulant therapy, and "conventional treatment" was otherwise limited to life style counseling, diuretics, digitalis, and supplemental oxygen (Naeije and Vachiery 2001). Chronic continuous intravenous prostacyclin (epoprostenol, Flo$\operatorname{lan}^{\circledR}$ ) was introduced in the 1980 s to bridge patients with idiopathic PAH (IPAH) to transplantation (Higenbottam et al 1993). Epoprostenol was thereafter shown by two randomized controlled trials to improve functional state, exercise capacity, and survival in idiopathic PAH (Barst et al 1996) and to improve functional state and exercise capacity in CTD-PAH (Badesch et al 2000). These trials led to the FDA approval of epoprostenol for New York Heart Association (NYHA) functional classes III and IV patients with IPAH in 1996, with label extension to include CTD-PAH in 2000.

Extensive experience of long-term treatment with chronic intravenous epoprostenol has confirmed persistent clinical benefit over years in IPAH (McLaughlin et al 2002; Sitbon et al 2002), CHD-PAH (Rosenzweig et al 1999), portal hypertension-associated PAH (Kuo et al 1997), and HIV-PAH (Nunes et al 2003). Good long-term results of chronic intravenous epoprostenol has led to withdrawal of PAH patients from waiting lists for transplantation (Robbins et al 1998). Intravenous epoprostenol has been reported to help bridging CTEPH patients to thromboendarterectomy (Nagaya et al 2003).

Chronic intravenous epoprostenol has been established as the gold standard of PAH therapy. It is recommended as first line for NYHA IV patients, and as add-on for patients remaining in NYHA functional class III in spite of correctly dosed ERA, PDE-5 inhibitors, or both (Galie et al 2004; Badesch et al 2007). However, the treatment is not ideal.

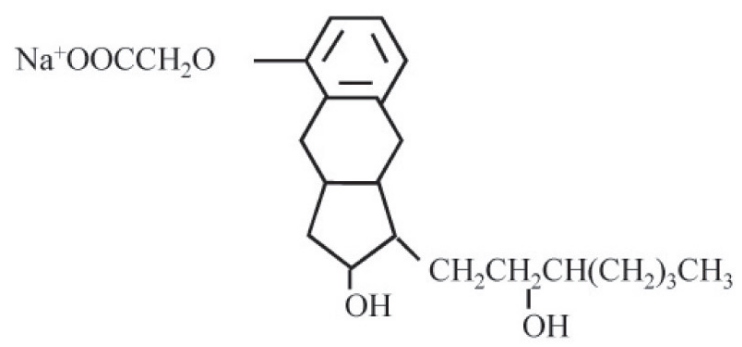

Because of instability and very short half-life (2-7 min), epoprostenol must be administered as a continuous infusion through a permanently implanted central venous catheter. This exposes the patients to a series of complications including catheter-related embolism or thrombosis, infections, and delivery system malfunctions resulting in poorly tolerated rapid overdosing or under-dosing. Therefore, more stable prostacyclin derivatives and different routes of administration have been developed. The first to be proposed as an alternative to intravenous epoprostenol has been subcutaneous treprostinil (Simonneau et al 2002).

\section{Pharmacology of treprostinil}

Treprostinil (see Figure 1) is a tricyclic benzindene analogue of prostacyclin, and has as such similar anti-platelet and vasodilatory actions, including acute pulmonary vasodilation (Vachiery and Naeije 2004). This prostanoid is rapidly and completely absorbed after subcutaneous administration with an absolute bioavailability of $100 \%$. Continuous subcutaneous infusion of treprostinil is associated with steady state plasma concentrations after about $10 \mathrm{~h}$ with administration rates from 1.25 to $22 \mathrm{ng} / \mathrm{kg} / \mathrm{min}$. The metabolism of treprostinil is hepatic, although the enzymes involved are not exactly known. Approximately $79 \%$ of the administered dose is excreted in the urine either as unchanged drug (4\%) or an identifiable metabolite (64\%). The safety of treprostinil is favorable, with in particular no reproductive toxicity or teratogenicity.

The clearance of treprostinil is decreased up to $80 \%$ in patients with hepatic insufficiency, requiring therefore cautious dosing in patients with PAH associated with liver disease. There are no studies on the pharmacokinetics of treprostinil in patients with renal insufficiency. Treprostinil does not interfere with the metabolism of paracetamol, warfarin, or digoxin (Wade et al 2003, 2004). Treprostinil is chemically stable in either sterile water or $0.9 \%$ sodium chloride and 5\% dextrose solutions at room temperature, and has a close to neutral pH (Phares et al 2003).

Figure I Chemical structure of treprostinil sodium (left) and epoprostenol sodium (right).

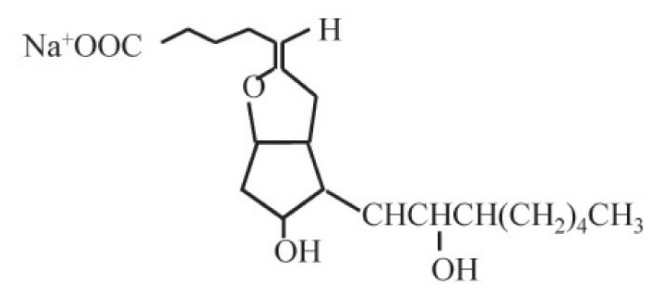


Subcutaneous treprostinil is advantageous compared to intravenous epoprostenol because of a less cumbersome delivery system and no need for a surgically implanted central venous line. Epoprostenol requires sterile daily or twice daily reconstitution with ice packing, and is administered with a variety of more or less bulky portable pump systems. In contrast, treprostinil is supplied in $20 \mathrm{~mL}$ vials containing either $1,2.5,5$, or $10 \mathrm{mg} / \mathrm{mL}$ that may be stored at room temperature. In addition, treprostinil is delivered via a mini-infusion pump, which is of the size of a small cell phone. The injection site is changed approximately every 3 days. However, while this is not recommended, many patients find it less painful to leave the subcutaneous catheter in place for longer periods of time, up to 2-3 weeks, and this seems to be generally well tolerated (Vachiery and Naeije 2004).

\section{The pivotal treprostinil trial}

The pivotal 12-week trial included 2 parallel North American and European international, multicenter, double-blind, randomized, parallel, placebo-controlled studies in a total of 470 patients aged 8-75 years with PAH (Simmoneau et al 2002). This has been until now the largest randomized controlled trial ever performed in PAH. The primary endpoint was exercise capacity as assessed by the 6-min walk distance. Principal reinforcing endopoints were a dyspnea-fatigue rating and a clinical score. The clinical score included a specified list of symptoms (dyspnea, orthopnea, fatigue, chest pain, dizziness, syncope, palpitations, and edema) and signs (loud pulmonic sound, right ventricular third sound, right ventricular fourth sound, right ventricular heave, tricuspid insufficiency murmur, pulmonic regurgitation murmur, hepatomegaly, and jugular vein distension at $45^{\circ}$ ). A simplified clinical score of only 5 of these items, ie, dyspnea, fatigue, chest pain, dizziness, syncope, was also used and proved equally sensitive to therapy. The secondary endpoints were the Borg score and hemodynamics (right atrial pressure, Ppa, Ppw, cardiac output heart rate, and mixed venous oxygenation saturation). Quality of life (QOL) was assessed using the Minnesota Living with Heart Failure questionnaire. Six-min walk test, Borg score, dyspnea-fatigue rating, clinical score, and QOL were obtained at baseline and 1,6 , and 12 weeks after randomization. The hemodynamic measurements were obtained at baseline and 12 weeks after randomization. The two studies were analyzed individually as well as together.

Treprostinil was initiated at a fixed dose of $1.25 \mathrm{ng} / \mathrm{kg} / \mathrm{min}$ (or half this dose if not tolerated), and then progressively increased if tolerated by $1.25 \mathrm{ng} / \mathrm{kg} / \mathrm{min}$ during the first 4 weeks, then by $2.5 \mathrm{ng} / \mathrm{kg} / \mathrm{min}$ per week until a maximum of $22.5 \mathrm{ng} / \mathrm{kg} / \mathrm{min}$ at week 12 . In fact, the final doses achieved remained below these target doses, at $9.3 \pm 0.4 \mathrm{ng} / \mathrm{kg} / \mathrm{min}$ in the treprostinil group, and $19.1 \pm 0.3 \mathrm{ng} / \mathrm{kg} / \mathrm{min}$ in the placebo group. This was explained by slowing of dose escalation because of infusion site pain.

The two study groups were comparable in age, gender distribution, and severity of pulmonary hypertension, with $82 \%$ of the patients in NYHA functional class III, $11 \%$ in NYHA class II, and 7\% in NYHA class IV, and an average baseline 6-min walk distance of $326 \mathrm{~m}$. Subsets of PAH were IPAH in $58 \%$ of the patients, CTD-PAH in 19\%, and CHD-PAH in $23 \%$.

In analyzing both studies together, the overall median 6-min walk increased by $10 \mathrm{~m}$ in the treprostinil group, and did not change in the placebo group, with a between-group effect of $16 \mathrm{~m}(\mathrm{p}=0.0064)$. It is interesting that the two studies did not reach a $\mathrm{p}<0.05$ level of significance on the placebo-substracted change in the 6-min walk distance ( $p=0.0607$ and 0.055 , respectively). The pre-specified criteria, ie, pooled $\mathrm{p}<0.01$ with one of the two trials with a $\mathrm{p}<0.05$, were not achieved, but it appeared reasonable to conclude that the results showed a treatment effect of treprostinil in $\mathrm{PAH}$, because of significant directional changes in all the reinforcing and secondary endpoints. As in other prostacyclin trials in IPAH or CTD-PAH, hemodynamic changes after 12 weeks of treatment, though significant, were relatively minor: in the treprostinil and placebo groups, respectively, Ppa +2.3 vs $-0.7 \mathrm{mmHg}$ and cardiac output +0.12 vs $-0.06 \mathrm{~L} / \mathrm{min} / \mathrm{m}^{2}$. On the other hand, both the 6-min walk distance and the clinical score was already significantly improved by treprostinil after 6 weeks of treatment, illustrating the relevance of the 6-min walk distance to detect clinical changes in PAH patients.

A covariate analysis showed no interactions between treprostinil treatment effect and age, gender, race, or diagnostic category. However, an a posteriori subgroup analysis showed similar responses to treprostinil in IPAH and CTDPAH, but no significant change in 6-min walk distance in CHD-PAH. This difference was explained by the inhomogeneous character of that subgroup, and also by the fact that CHD-PAH tends to be stable for much longer periods of time than other PAH categories. On the other hand, there were significant interactions between treprostinil treatment effect and NYHA functional class, baseline 6-min walk distance, and $\mathrm{SvO}_{2}$. The 6-min walk distance was improved by $54 \mathrm{~m}$ in the 34 patients in NYHA class IV, $17 \mathrm{~m}$ in the 382 patients 
in NYHA class III, and only $2 \mathrm{~m}$ in the 53 patients who were in NYHA class II.

In fact, there was a dose relationship such that the higher the treprostinil dose achieved, the greater the increase in 6-min walk distance. Based on this observation, the average dose achieved in the treprostinil group was only 9.3 $\mathrm{ng} / \mathrm{kg} / \mathrm{min}$, far below the target $22.5 \mathrm{ng} / \mathrm{kg} / \mathrm{min}$ dosing, thereby preventing full disclosure of treprostinil efficacy. It was indeed only later the experience of many centers that infusion site pain is not directly dependent on the rate of treprostinil dose increase.

Infusion site pain occurred in $85 \%$ of the treprostiniltreated patients and in $27 \%$ in the placebo-treated patients. Eighteen patients ( $8 \%$ ) in the treprostinil group discontinued their study treatment due to intolerable abdominal infusion site pain versus one in the placebo group. Other adverse events were those classically related to the use of prostacyclin such as diarrhea, jaw pain, flushing, and lower limb edema, which mainly occurred more often in the treprostinil group. There were no other significant side effects.

\section{Long-term observations}

The effects of long-term subcutaneous treprostinil have been reported in 860 patients with PAH (Barst et al 2006). In that study, the initial clinical improvement was sustained in the majority of patients, and survival was globally $87 \%$ at 1 year and $68 \%$ at 4 years, with $91 \%-72 \%$ for a subset of IPAH patients. In $23 \%$ of the patients, the treatment was discontinued because of adverse events, and in $11 \%$ switched to an alternative prostacyclin analogue. Bosentan was added in 105 patients (12\%) and sildenafil in $25(3 \%)$.

In another long-term observational study on a total of 99 PAH patients and 23 inoperable CTEPH patients, the NYHA functional class declined from 3.2 to 2.1 with persistent improvement in the 6-min walk distance, on average by $100 \mathrm{~m}$ (Figure 2). The 1- and 3-year survival rates were $89 \%$ and $71 \%$, with, interestingly, event-free survival rates of $83 \%$ and $69 \%$. The mean dose of treprostinil at 3 years was on average around $40 \mathrm{ng} / \mathrm{kg} / \mathrm{min}$ (Figure 3). There were only $5 \%$ of treatment interruptions because of local infusion site pain.

These long-term observations suggest that subcutaneous treprostinil is a valid alternative to intravenous epoprostenol as a gold standard of PAH therapy (Galie et al 2004; Badesch et al 2007).

\section{Transitioning}

Transition from intravenous epoprostenol to subcutaneous treprostinil has been achieved in a number of patients. Initially undertaken because of life-threatening complications of chronic intravenous epoprostenol therapy, such as embolic stroke and repeated sepsis (Vachiery et al 2002), the procedure is now also performed in several centers on the request of patients for the purpose of increased autonomy and comfort. Transitioning should be performed in a hospital environment

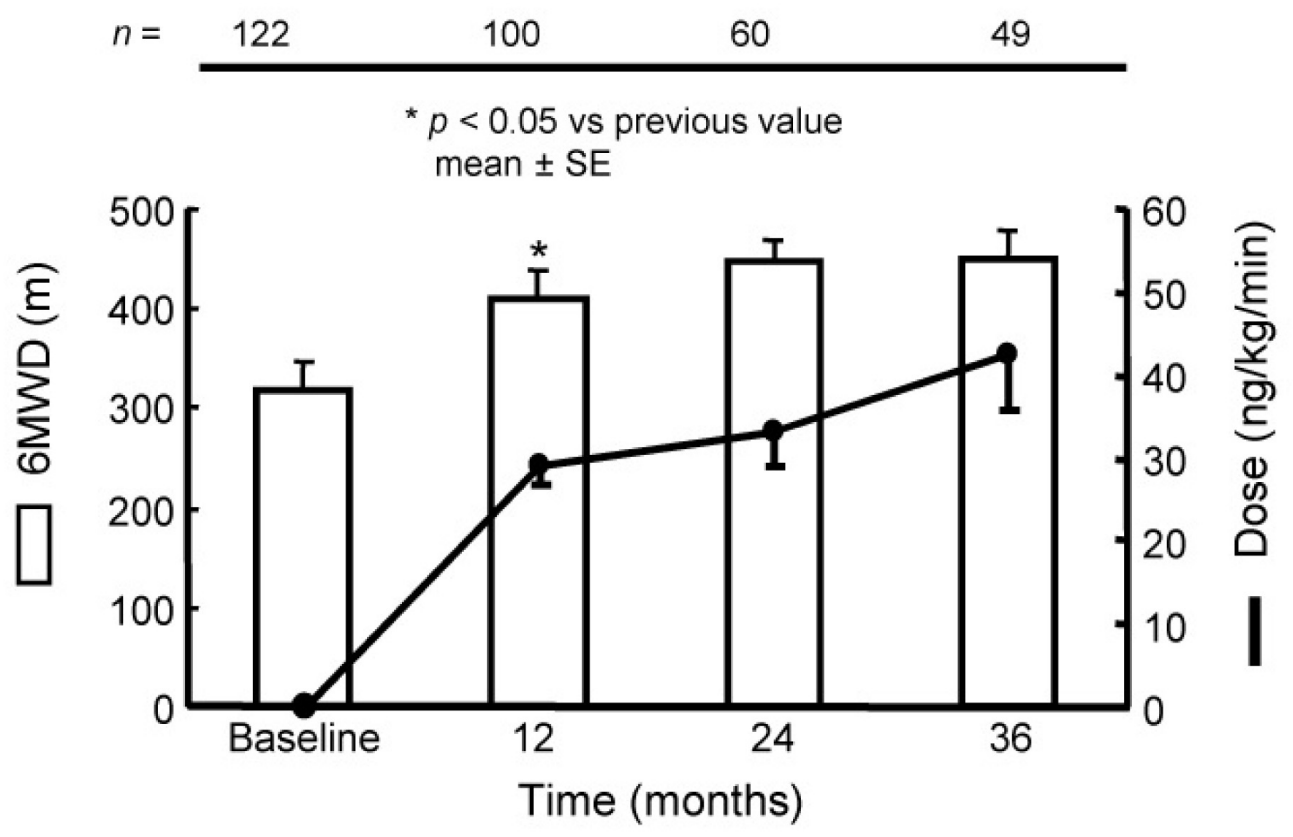

Figure 2 Long-term effects of subcutaneous treprostinil on exercise capacity in patients with severe pulmonary hypertension, with indication of treprostinil dose and 6MWD (6-min walk distance). Drawn from data of Lang et al (2006). 
under the supervision of a medical team experienced in the treatment of PAH. Under noninvasive hemodynamic monitoring including heart rate and blood pressure measurements and echocardiography as needed, epoprostenol is progressively decreased and treprostinil increased, with overdosing and underdosing symptoms-directed adjustments, in no more than 1-4 days. Usually the same clinical state and exercise capacity is obtained under a treprostinil dose that is about $80 \%$ of the previous epoprostenol dose. Most transitioned patients express satisfaction and relief, in spite of local infusion site pain, and present with continued improvement in exercise capacity over time.

There has been recently a report on $22 \mathrm{PAH}$ patients treated with intravenous epoprostenol who were randomized for 8 weeks to subcutaneous treprostinil versus a placebo (Rubenfire et al 2007). This represents the only withdrawal trial reported in PAH. Even though the protocol specified that patients with clinical deterioration would be rapidly returned to intravenous epoprostenol, most experts would be reluctant to repeat such a study. Patients who deteriorate after interruption of any prostacyclin therapy may be difficult to bring back to their previous clinical state. However, no irreversible deterioration occurred in this tightly monitored trial. Seven of the 8 patients withdrawn to placebo had the expected clinical deterioration, while this was observed in only 1 of the 14 patients withdrawn to subcutaneous treprostinil. The authors concluded that subcutaneous treprostinil is effective in $\mathrm{PAH}$ and maintains functional status in patients transitioned from intravenous epoprostenol (Rubenfire et al 2007).

Treprostinil can be formulated for intravenous administration. Intravenous treprostinil has been reported to improve exercise capacity, Borg dyspnea score, NYHA functional class, and hemodynamics after 12 weeks of therapy compared with baseline (Tapson et al 2006). Accordingly, patients treated with intravenous epoprostenol have been safely switched to intravenous treprostinil (Gomberg-Maitland et al 2005; Sitbon et al 2007). However, while the dosing of subcutaneous treprostinil is about the same as that of intravenous epoprostenol (Vachiery et al 2002), the dose of intravenous treprostinil has been reported to be at least doubled to maintain the clinical benefit (Gomberg-Maitland et al 2005; Sitbon et al 2007). Patients have also been switched from subcutaneous to intravenous treprostinil in several PAH centers, with the same apparent need to rapidly double the dose to attain similar efficacy. There is no explanation for this discrepancy, as bioequivalence of intravenous and subcutaneous treprostinil has been reported in normal volunteers at steady state, after 72 hours of continuous administration (Labilerte et al 2004). Most recently, this bioequivalence, with the same dose versus plasma levels relationship, was confirmed for $\mathrm{PAH}$ patients over a wide range of therapeutic doses, up to $125 \mathrm{ng} \mathrm{kg} / \mathrm{min}$ (McSwain et al 2008). The problem of optimal dosing with intravenous versus subcutaneous treprostinil in

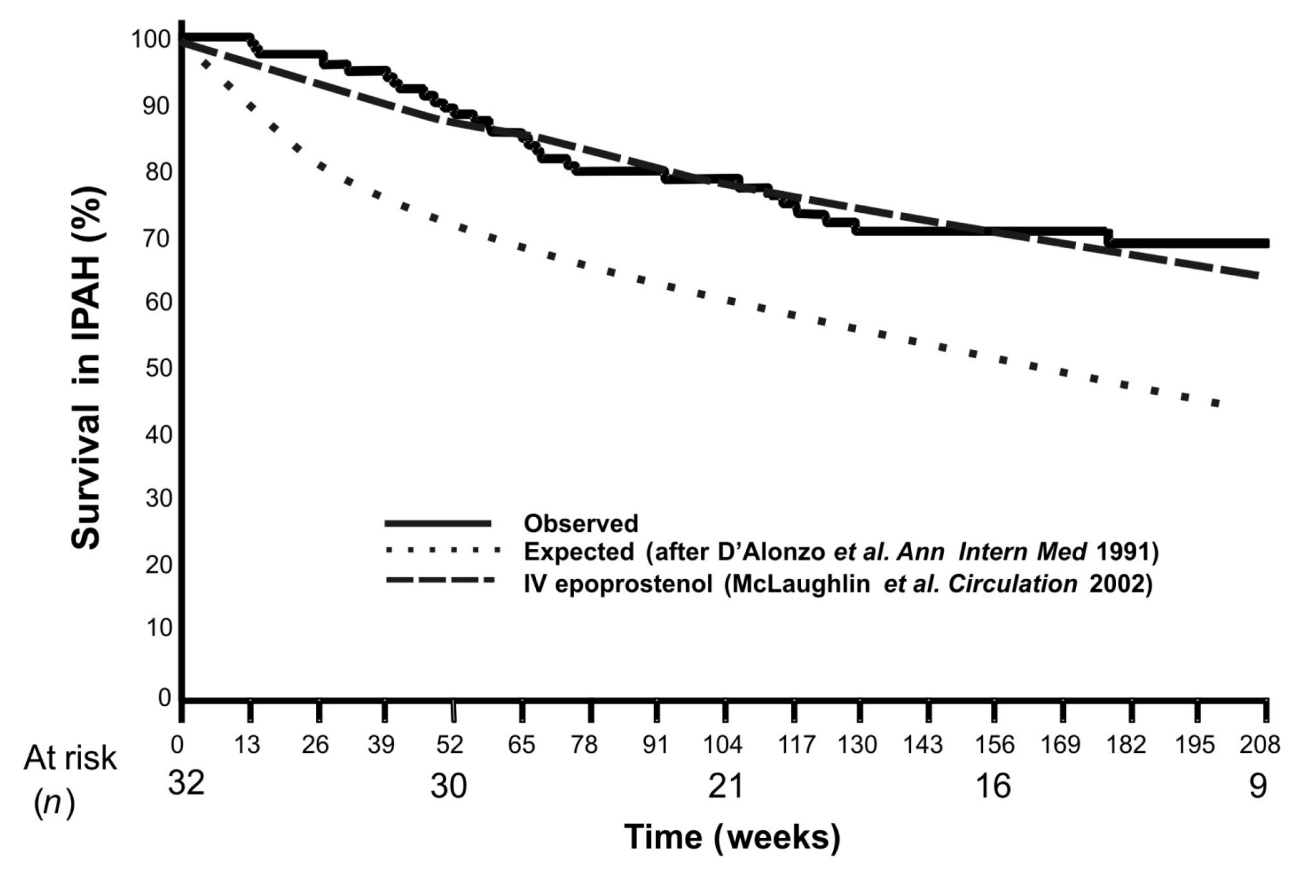

Figure 3 Effects of subcutaneous treprostinil on survival in patients with idiopathic pulmonary arterial hypertension (PAH). Survival curves of similar patients treated with intravenous epoprostenol and those of historical controls are also shown. Drawn from data of McLaughlin et al (2002) and Lang et al (2006). 
PAH patients may have to be revisited with the complete range of clinical and hemodynamic endpoints usually applied in PAH trials (Simmoneau et al 2002).

Any continuous drug administration through an implanted central venous catheter carries a risk of line infection and sepsis. While the overall incidence of this severe complication is very low, there has been a recent concern about an increased number of gram-negative bloodstream infections in patients treated with intravenous treprostinil compared with intravenous epoprostenol (CDC 2007). This problem appears to be related to differences in preparation and storage, and should be overcome by tightening of sterility precautions.

An inhaled formulation of treprostinil is currently being evaluated with encouraging preliminary results (Channick et al 2006). The preliminary results of a randomized controlled trial of inhaled treprostinil on top of bosentan or sildenafil therapies have been reported as a press release, with a significance on the primary endpoint, the 6-min walk distance. A more detailed report on these results will be hopefully presented soon at a scientific meeting. Randomized controlled trials of an oral formulation of treprostinil are ongoing.

\section{Treprostinil for CTEPH}

As already mentioned, subcutaneous treprostinil has been occasionally used to treat patients with inoperable CTEPH (Lang et al 2006). The rationale is that pulmonary hypertension in these patients may be essentially accounted for by distal vasculopathy, which is actually hispathologically similar to PAH (Hoeper et al 2006). The effects of subcutaneous treprostinil have been recently reported in 25 inoperable CTEPH patients included in an open-label uncontrolled study (Skoro-Sajer et al 2007). All patients were in NYHA functional classes III or IV, had a 6-min walk distance of less than $380 \mathrm{~m}$, and had undergone at least 1 previous hospitalization for right heart failure within the previous 6 months. The patients were compared to matched historical inoperable CTEPH controls. The patients were followed for $19 \pm 6$ months. Treprostinil treatment improved survival, increased the 6-min walk distance, improved NYHA functional class, decreased B-type natriuretic peptide, increased cardiac output and decreased PVR. Treprostinil plasma levels correlated with drug dose over time, indicating persistently stable absorption, in spite of local reactions in $86 \%$ of cases. Thus, subcutaneous treprostinil shows as an interesting therapeutic option for patients with inoperable CTEPH. Subcutaneous treprostinil offers perspective for the treatment of persistent postoperative pulmonary hypertension, or for the preoperative conditioning of patients for surgery in case of excessively high PVR, known to be a poor operative risk. However, these possible indications will have to be confirmed in properly designed randomized controlled trials.

\section{Indications and usage}

Chronic subcutaneous treprostinil has a place in the treatment algorithm of patients with PAH in functional classes II, III, and IV (Galie et al 2004; Badesch et al 2007).

The recommendation is to start treprostinil at the dose of $1.25 \mathrm{ng} / \mathrm{kg} / \mathrm{min}$, which is increased by $1.25 \mathrm{ng} / \mathrm{kg} / \mathrm{min}$ per week during the first 4 weeks, then by $2.5 \mathrm{ng} / \mathrm{kg} / \mathrm{min}$ per week until the maximum clinical improvement with no excessive prostacyclin-type side effects. However, in practice most centers now start at $2.5 \mathrm{ng} / \mathrm{kg} / \mathrm{min}$ and increase in a few days to reach $10 \mathrm{ng} / \mathrm{kg} / \mathrm{min}$ after a week and $15-20 \mathrm{ng} / \mathrm{kg} / \mathrm{min}$ after 2 weeks according to tolerance. Weekly adaptations are applied afterwards, aiming at optimal clinical efficacy with minimal side effects. This strategy appears to be safe, allows for more rapid and effective relief in severely ill patients, and outruns the local infusion site pain, which is of course better tolerated in the context of decreased dyspnea and fatigue.

Local infusion site pain will occur in around $80 \%$ of patients, and may be intolerable in $6 \%-15 \%$ of them. It varies markedly from one patient to another, from one infusion site to another, is primarily related to initiation of infusion, and often, but not always, improves after several months. It is usually worse during the first days following a change of infusion site, and may sometimes impair the ability of a patient to perform a 6-min walk test. It has been our experience that the administration of more concentrated solutions, starting with $2.5 \mathrm{mg} / \mathrm{mL}$ to progress as soon as possible to the use of $5 \mathrm{mg} / \mathrm{mL}$ or $10 \mathrm{mg} / \mathrm{mL}$ vials, decreases the local pain by decreasing the amount of volume infused for the same dose. The pain is otherwise generally manageable by relocation of infusion site, cold or hot compresses, a variety of local ointments, and paracetamol. Sometimes, a short course of high dose corticosteroids, such as prednisolone $2 \mathrm{mg} / \mathrm{kg} /$ day during several days, may help the patient through, and narcotic drugs have been used in some centers. These more aggressive interventions may appear necessary when patients present with severe pain that reduces quality of life. In these cases, especially if on high dose treprostinil, transitioning to intravenous epoprostenol may fail because of major prostacyclin-type side effects of equivalent dose intravenous epoprostenol, and carries the risk of clinical destabilization. It is therefore preferable to switch from 
subcutaneous to intravenous treprostinil, bearing in mind that higher doses may be needed, and particular attention should be paid to sterility of manipulations.

It has been the experience in expert centers in general that prostacyclin-type side effects tend to be less severe with treprostinil than with epoprostenol, allowing for more rapid increase in dosing and symptomatic relief. The reasons for this better tolerance of treprostinil are unclear, but may be related to less rapid increases in plasma levels.

\section{Disclosures}

None of the authors has any conflicts of interest to disclose.

\section{References}

Badesch DB, Abman SH, Simonneau G, et al. 2007. Medical therapy for pulmonary arterial hypertension: updated ACCP evidence-based clinical practice guidelines. Chest, 131:1917-28.

Badesch DB, Tapson VF, McGoon MD, et al. 2000. Continuous intravenous epoprostenol for pulmonary hypertension due to the scleroderma spectrum of disease. A randomized, controlled trial. Ann Intern Medi, 132:425-34.

Barst RJ, Galie N, Naeije R, et al. 2006. Long-term outcome in pulmonary arterial hypertension patients treated with subcutaneous treprostinil. Eur Respir J, 28:1195-203.

Barst RJ, Rubin LJ, Long WA, et al. 1996. A comparison of continuous intravenous epoprostenol (prostacyclin) with conventional therapy for primary pulmonary hypertension. $N$ Engl J Med, 334:296-301.

Centers for Disease Control and Prevention (CDC). 2007. Bloodstream infections among patients treated with intravenous epoprostenol or intravenous treprostinil for pulmonary arterial hypertension, seven sites, United States. Morb Mortal Wkly Rep, 56:170-2.

Channick RN, Olschewski H, Seeger W, et al. 2006. Safety and efficacy of inhaled treprostinil as add-on therapy to bosentan in pulmonary arterial hypertension. J Am Coll Cardiol, 48:1433-7.

Farber HW, Loscalzo J. 2004. Pulmonary arterial hypertension. $N$ Engl $J$ Med, 351:1655-65.

Galie N, Torbicki A, Barst R, et al. Task Force. 2004. Guidelines on diagnosis and treatment of pulmonary arterial hypertension. The Task Force on Diagnosis and Treatment of Pulmonary Arterial Hypertension of the European Society of Cardiology. Eur Heart J, 25:2243-78.

Gomberg-Maitland M, Tapson VF, Benza RL, et al. 2005. Transition from intravenous epoprostenol to intravenous treprostinil in pulmonary hypertension. Am J Respir Crit Care Med, 172:1586-9.

Higenbottam TW, Spiegelhalter D, Scott JP, et al. 1993. Prostacyclin (epoprostenol) and heart-lung transplantation as treatments for severe pulmonary hypertension. Br Heart J, 70:366-70.

Hoeper MM, Mayer E, Simonneau G, et al. 2006. Chronic thromboembolic pulmonary hypertension. Circulation, 113:2011-20.

Humbert M, Sitbon O, Simonneau G. 2004. Treatment of pulmonary arterial hypertension. N Engl J Med, 351:1425-36.

Humbert M, Sitbon O, Chaouat A, et al. 2006. Pulmonary arterial hypertension in France: results from a national registry. Am J Respir Crit Care Med, 173:1023-30.

Kuo PC, Plotkin JS, Howell CD, et al. 1997. Continuous infusion of epoprostenol for the treatment of portopulmonary hypertension. Transplantation, 63:604-6.

Laliberte K, Arneson C, Jeffs R, et al. 2004. Pharmacokinetics and steady-state bioequivalence of treprostinil sodium (Remodulin) administered by the intravenous and subcutaneous route to normal volunteers. J Cardiovasc Pharmacol, 44:209-14.
Lang I, Gomez-Sanchez M, Kneussl M, et al. 2006. Efficacy of long-terms subcutaneous treprostinil sodium therapy in pulmonary hypertension. Chest, 129:1636-43.

McLaughlin V, Presberg KW, Doyle RL, et al. 2004. Prognosis of pulmonary arterial hypertension* ACCP evidence-based clinical practice guidelines. Chest, 126:78S-92S.

McLaughlin VV, Shillington A, Rich S. 2002. Survival in primary pulmonary hypertension: the impact of epoprostenol therapy. Circulation, 106:1477-82.

McSwain CS, Benza R, Shapiro S, et al. 2008. Dose proportionality of treprostinil sodium administered by continuous subcutaneous and intravenous infusions. J Clin Pharmacol, 48:19-25.

Naeije R, Vachiery JL. 2001. Medical therapy of pulmonary hypertension: conventional therapies. Clin Chest Med, 22:517-28.

Nagaya N, Sasaki N, Ando M, et al. 2003. Prostacyclin therapy before pulmonary thromboendarterectomy in patients with chronic thromboembolic pulmonary hypertension. Chest, 123:338-43.

Nunes H, Humbert M, Sitbon O, et al. 2003. Prognostic factors for survival in human immunodeficiency virus-associated pulmonary arterial hypertension. Am J Respir Crit Care Med, 167:1433-9.

Peacock AJ, Murphy NF, McMurray JJV, et al. 2007. An epidemiological study of pulmonary arterial hypertension. Eur Respir J, 30:104-9.

Phares KR, Weiser WE, Miller SP, et al. 2003. Stability and preservative effectiveness of treprostinil sodium after dilution in common intravenous diluents. Am J Health Syst Pharm, 60:916-22.

Provencher S, Sitbon O, Humbert M, et al. 2006. Long-term outcome with first-line bosentan therapy in idiopathic pulmonary arterial hypertension. Eur Heart J, 27:589-595.

Robbins IM, Christman BW, Newman JH, et al. 1998. A survey of diagnostic practices and the use of epoprostenol in patients with primary pulmonary hypertension. Chest, 114:1269-75.

Rosenzweig EB, Kerstein D, Barst RJ. 1999. Long-term prostacyclin for pulmonary hypertension with associated congenital heart defects. Circulation, 99:1858-65.

Rubenfire M, McLaughlin VV, Allen RP, et al. 2007. Transition from IV epoprostenol to subcutaneous treprostinil in pulmonary arterial hypertension: a controlled trial. Chest, 132:757-63.

Simonneau G, Barst RJ, Galié N, et al. 2002. Continuous subcutaneous infusion of treprostinil, a prostacyclin analogue, in patients with pulmonary arterial hypertension. Am J Respir Crit Care Med, 162:800-4.

Simonneau G, Galie N, Rubin LJ, et al. 2004. Clinical classification of pulmonary hypertension. J Am Coll Cardiol, 43(12 Suppl S):5S-12S.

Sitbon O, Humbert M, Nunes H, et al. 2002. Long-term intravenous epoprostenol infusion in primary pulmonary hypertension: prognostic factors and survival. J Am Coll Cardiol, 40:780-8.

Sitbon O, Manes A, Jais X, et al. 2007. Rapid switch from intravenous epoprostenol to intravenous treprostinil in patients with pulmonary arterial hypertension. J Cardiovasc Pharmacol, 49:1-5.

Skoro-Sajer N, Bonderman D, Wiesbauer F, et al. 2007. Treprostinil for severe inoperable chronic thromboembolic pulmonary hypertension. $J$ Thomb Haemost, 5:483-9.

Tapson VF, Gomberg-Maitland M, McLaughlin VV, et al. 2006. Safety and efficacy of iv treprostinil for pulmonary arterial hypertension: a prospective, multicenter, open-label, 12-week trial. Chest, 129:683-8.

Vachiery JL, Hill N, Zwicke D, et al. 2002. Transitioning from i.v. epoprostenol to subcutaneous treprostinil in pulmonary arterial hypertension. Chest, 121:1561-5.

Vachiery JL, Naeije R. 2004. Treprostinil for pulmonary hypertension. Expert Rev Cardiovasc Ther, 2:183-91.

Wade M, Baker FJ, Roscigno R, et al. 2004. Absolute bioavailability and pharmacokinetics of treprostinil sodium administered by acute subcutaneous infusion. J Clin Pharmacol, 44:83-8.

Wade M, Hunt TL, Lai AA. 2003. Effect of continuous subcutaneous treprostinil therapy on the pharmacodynamics and pharmacokinetics of warfarin. $J$ Cardiovasc Pharmacol, 41:908-15. 
